\title{
Design of molecular ferromagnets
}

\author{
J V YAKHMI* and S A CHAVAN \\ Chemistry Division, Bhabha Atomic Research Centre, Mumbai 400 085, India
}

\begin{abstract}
A large variety of molecular ferromagnets have been synthesized since the discovery of the first organic ferromagnets, including pure organic compounds, organometallic charge-transfer complexes, metal complex-organic radical compounds, and transition metal complexes coupled to organic radicals. Besides, there are many reports on the observation of ferromagnetism in polymers and organic matrix composites. Molecular ferromagnets have great potential in different areas of technology such as low frequency magnetic shielding, magnetic imaging, magneto-optics and information storage. We provide a brief review on the current strategies for the design of molecular (organic) ferromagnets. This includes exploiting the inherent advantages of molecular systems, such as the ability to fine-tune the properties at the molecular level, and to control dimensionality, supramolecular structuring and hierarchy of spin interactions etc. for carrying out structural modifications and chemical functionalisations of stable open-shell molecules in order to generate supramolecular structures in which the natural prediction for antiparallel spin alignment (antiferromagnetism) is avoided.
\end{abstract}

Keywords. Organic ferromagnets; polymers; ferrimagnetic subunits; charge transfer complexes; dimensionality; hydrogen bonding.

\section{Introduction}

Ferromagnetic behaviour arises when unpaired spins in a material align collectively in the same direction resulting in a net magnetic moment and spontaneous magnetization below a characteristic temperature, $T_{c}$, called the Curie temperature. Ideally, in such structures, the spin carriers (viz. (i) organic radicals, where the unpaired spins reside in the $p$ orbitals only; (ii) transition metal ions having their unpaired spins in the $d$ orbitals; and (iii) their hybrids in which the unpaired spins are in both $p$ and $d$ orbitals) need to be incorporated into molecules which are functionalised so that when these molecules assemble in a $2 \mathrm{D}$ - or preferably a $3 \mathrm{D}$ - network, a ferromagnetic interaction may arise between the constituent molecules. However, synthesis of such materials is not easy because unlike most conventional magnetic materials used in modern technology such as, $\mathrm{Fe}, \mathrm{CrO}_{2}, \mathrm{Fe}_{2} \mathrm{O}_{3}, \mathrm{SmCO}_{5}, \mathrm{Sm}_{2} \mathrm{O}_{17}$ or $\mathrm{Nd}_{2} \mathrm{Fe}_{14} \mathrm{~B}$, which are all atom-based materials, the molecular magnets under discussion are made up of discrete molecules and are mostly organic compounds, being essentially closed-shell structures and therefore diamagnetic. Even if one or more unpaired electrons are'maintained stably in a given organic molecule, they prefer to get antiferromagnetically coupled with those on the adjacent radicals, owing to the orthogonality condition. Hund's rule allows a ferromagnetic alignment of the two spins only if the orbitals containing the

\footnotetext{
*For correspondence
} 
unpaired electrons on the two spin-centres are orthogonal to each other, any non-zero overlap between orbitals leads to an antiparallel alignment of spins.

A theoretical proposal to design organic ferromagnets was made by McConnell (1963), according to which if two radicals A and B are packed such that the negative spin density sites of one radical locate directly above the positive spin density of the other, then the Heisenberg Hamiltonian for the interacting spins can be written as

$$
H_{\mathrm{AB}}=-2 \sum_{i j} J_{i j}^{\mathrm{A}} S_{i}^{\mathrm{A}} S_{j}^{\mathrm{B}}=-2 S^{\mathrm{A}} S^{\mathrm{B}} \sum_{i j} J_{i j} \rho_{i}^{\mathrm{A}} \rho_{j}^{\mathrm{B}},
$$

and the effective exchange interaction between the two radicals will be ferromagnetic when the product of spin densities $\rho_{i}$ and $\rho_{j}$ at sites $i$ and $j$ on $A$ and $\mathrm{B}$ is negative. A second mechanism for the kinetic stabilization of a triplet state proposed by McConnell (1967) is based on the configuration interaction of the wavefunction of a virtual excited state with the wavefunction of the triplet ground state. However, it is only during the last decade that a variety of molecule-based ferromagnetic materials have been synthesized successfully by controlling the interactions between different magnetic centres during synthesis (Miller et al 1986, 1988a,b; Caneschi et al 1989a; Kahn et al 1992; Yakhmi 1992; Kahn 1993; Gatteschi et al 1994; Miller and Epstein 1994; Chavan et al 1995a). Using synthetic organic chemistry, however, one can exercise immense flexibility in controlling the relative positions of the molecular units within a molecular lattice. Intermolecular interactions being weaker than the energies of typical covalent bonds, the molecules prefer to retain their individual characteristcs in a molecular solid. The properties of a molecular lattice are, therefore, derivable from those of the individual molecules and one should, in principle, be able to fine-tune its magnetic properties. The ultimate goal is to synthesize chemically stable molecular ferromagnets with $T_{\mathrm{c}}$ well above room temperature and magnetic characteristics optimized for applications. Being mostly organic in nature, they are lightweight, and easy to process and fabricate, and being soluble in organic solvents, can be exploited as liquid magnets, colloidal dispersions or Langmuir-Blodgett films. The possibility of perpendicular magnetic recording by their use makes them candidates for high density data storage. Their transparency in many spectral regions makes them suitable for photomagnetic switches and optical data storage. Besides, their "soft" magnetic nature and magnetorestrictive response makes them attractive for applications in shielding, AC-motors, generators and transformers. In what follows, we provide a brief review on different categories of organic ferromagnets while highlighting current strategies adopted for their synthesis

\section{Polymers}

Mataga (1968) and subsequently Ovchinnikov (1978) proposed a model for the possibility of ferromagnetic order in $\pi$-conjugated organic polymers having two sublattices. If, in a unit cell, the number of atoms belonging to the two sublattices are not equal, then there is a net spin for the unit cell giving rise to a high-spin ground state, examples of which are polycarbenes with $S=9$ which have indeed been synthesized (Nakamura et al 1993) but the synthesis of a bulk ferromagnetic polymer remains a distant goal. According to Ovchinnikov's model, free radicals (say phenoxy) if attached to the polyacetylene chain as pendants should interact ferromagnetically, yielding high spin polymers (figure la). However, pendant groups located thus have 


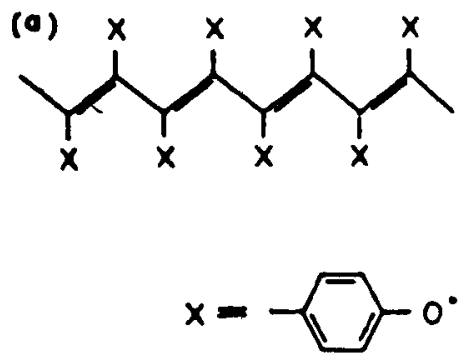<smiles>CC1(C)CC(O)(C#CC#CC2(O)CC(C)(C)N([O])C(C)(C)C2)CC(C)(C)C1[O]</smiles>

Figure 1. (a) Poly[4-oxyphenyl)acetylene] molecule where $X$ is a phenoxy free radical attached as pendant to the polyacetylene chain. Such molecules were suggested to become high-spin polymers by Ovchinnikov (1978), (b) Schematic of poly-BIPO structure.

(a)

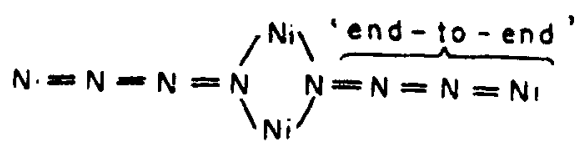

$$
\begin{aligned}
& \text { end-on' }
\end{aligned}
$$

(b)

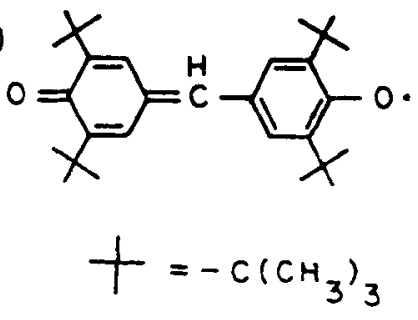

Figure 2. (a) End-to-end or end-on coordinations of azido group to Ni (II) ions. (b) Molecular structure of galvinoxyl.

"direct" through-space interaction, due to close proximity, giving rise to antiferromagnetism. Phenoxy radicals if placed as pendants on alternate sites should, in principle, lead to "indirect" through-bond exchange interaction and a ID ferromagnet (Yoshizawa et al 1993). A polymer ferromagnet poly-BIPO based on a polyacetylene chain (figure 1b) with a $T_{\mathrm{c}}$ value as high as $420-460 \mathrm{~K}$ was indeed synthesized by Ovchinnikov and co-workers (Korshak et al 1986, 1987), although only a very tiny volume fraction (0-1\%) of the sample was ferromagnetic. A rigorous theoretical treatment which takes into account the itinerancy of the chain $\pi$-electrons and also the strong electron-photon and electron-electron correlations (Fang et al 1994) has confirmed that the ground state is indeed a stable ferromagnetic state but a Peierls distortion overtakes and these $\pi$-electrons ultimately prefer to form an antiferromagnetic (SDW) state.

During the last few years, there have been a number of reports of observation of ferromagnetism in polymers at room temperature, namely pyrolysed polyacrylonitrile (PAN) (Katulevskii et al 1991), indigo polymer (Tanaka et al 1990) and triarylmethane resins (Ota et al 1989). However, the volume fraction of the ferromagnetic component in all the cases is low ( $<3 \%$ ), and the $M(H)$ hysteresis loop, if observed, shows little width with poor values of saturation magnetization and coercive field. Majority of these reported polymer ferromagnets suffer from non-reproducibility and poor chemical characterization, although in certain cases the samples do get attracted towards a horseshoe magnet at room temperature. A welcome trend is that radically new approaches are currently being tried to tune bulk ferromagnetism in polymers. For instance, the azido group if coordinated to two $\mathrm{Ni}$ (II) ions in an end-on fashion can give rise to a ferromagnetic coupling (figure $2 a$ ) whereas end-to-end coordination leads to 


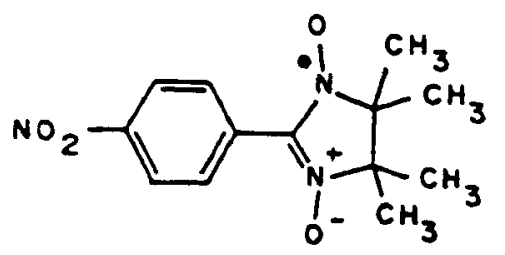

Figure 3. The chemical structure of $p$-NPNN. The black dot indicates an unpaired electron.

antiferromagnetic coupling. Using this idea, Ribas et al (1994) have been able to tune long-range ferromagnetism (though weak) below $60 \mathrm{~K}$ in an infinite bidimensional polymer $\mathrm{Ni}\left(\mathrm{N}_{3}\right)_{2}$ (2,2-dimethylpropane-1,3-diamine) $]_{n}$. Dougherty's group at Caltech (Murray et al 1994) has been able to establish ferromagnetic spin alignment along polymer chains when polaronic spin-containing units are coupled through suitable coupling units, although synthesis of a $3 \mathrm{D}$ bulk ferromagnet from such $1 \mathrm{D}$ prototypes is yet to be achieved.

\section{Purely organic radical clusters/compounds}

The galvinoxyl radical $\left(\mathrm{C}_{29} \mathrm{H}_{41} \mathrm{O}_{2}\right)$ (figure 2b) is known to exhibit ferromagnetic intermolecular interactions with positive paramagnetic Curie temperature $\left(\theta_{\mathrm{p}}=18 \mathrm{~K}\right)$, but the paramagnetic susceptibility disappears below $85 \mathrm{~K}$ (Awaga et al 1986). Galvinoxyl as well as tanol suberate $\left(\mathrm{C}_{26} \mathrm{H}_{46} \mathrm{~N}_{2} \mathrm{O}_{6}\right)$ radicals are truly speaking metamagnetic, exhibiting only $2 \mathrm{D}$ ferromagnetic behaviour in the ac-plane. but antiferromagnetic alignment along the $b$-direction.

Bulk ferromagnetism has been reported in purely organic (containing only $\mathrm{C}, \mathrm{H}, \mathrm{N}$, and O) material $\beta$-phase of $p$-NPNN ( $p$-nitrophenyl nitronyl nitroxide) (figure 3 ), the structural and magnetic characterization of which has been established but the Curie temperature is only $0.6 \mathrm{~K}$ (Tamura et al 1991; Nakazawa et al 1992). Ferromagnetism has also been reported for the $\alpha$-phase of HQNN, another nitronyl nitroxide derivative (Sugawara et al 1994). The highest Curie temperature for a purely organic non-ionic material has been reported as $1.48 \mathrm{~K}$ for the nitroxide biradical $\mathrm{N}, \mathrm{N}^{\prime}$-dioxyl-1,3,5,7tetramethyl-2,6-diazaadamantane arising from a 3D ferromagnetic order, though it exhibits no magnetic hysteresis (Chiarelli et al 1993). Ferromagnetism arising from 2D ordering of radical spins has also been reported recently for 4-benzylideneaminoTEMPO $\left(T_{\mathrm{c}}=0.18 \mathrm{~K}\right)$ (Nogami et al 1994) and 4-( $p$-phenylbenzylideneamino)TEMPO $\left(T_{c}=0.4 \mathrm{~K}\right)$ (Ishida et al 1994), where TEMPO stands for 2,2,6,6,-tetramethylpiperidin-1-oxyl.

In fullerene based molecular material tetrakis(dimethylamino) ethylene- $\mathrm{C}_{60}$, too, ferromagnetism was reported at 16.1 K (Allemand et al 1991; Stephens et al 1992), but it is a soft ferromagnet with no practical value since it displays S-shaped $M(H)$ curves with absence of hysteresis, coercivity and remanence. Films of polymer (PVDF)- $\mathrm{C}_{60}$ composite have recently been reported to exhibit ferromagnetism with measurable hysteresis at room temperature $\left(T_{\mathrm{c}}=350 \mathrm{~K}\right.$ ) (Ata et al 1994).

\section{Charge transfer salts}

The first organic ferromagnet to be synthesized was the charge-transfer salt, decamethylferrocenium tetracyanoethenide, $\left[\mathrm{Fe}^{\mathrm{III}}\left(\mathrm{C}_{5} \mathrm{Me}_{5}\right)_{2}\right]^{+}[\mathrm{TCNE}]^{-}$(Chittipedi 
(o)

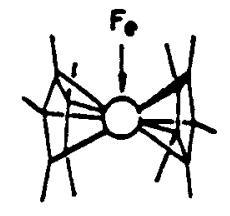

(b)

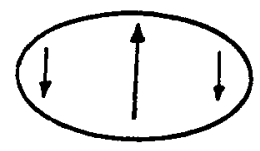

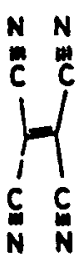
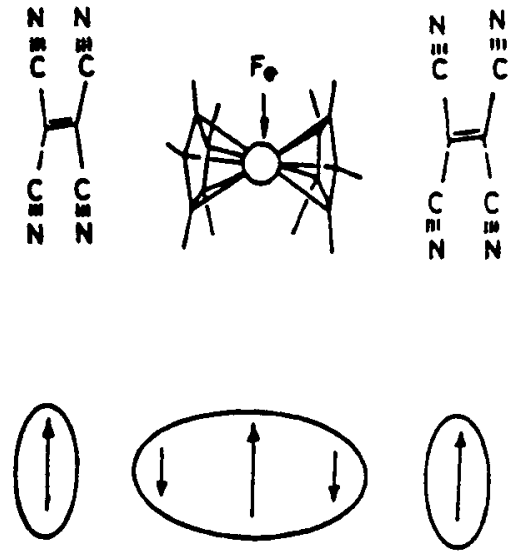

Figure 4. Stacking of $\left[\mathrm{Fe}^{I I I}\left(\mathrm{C}_{5} \mathrm{Me}_{5}\right)_{2}\right]^{+}$and $[\mathrm{TCNE}]^{-}$ions each having a spin $S=1 / 2$ (a), and schematic of spin polarisation in the donor units (b).

et al 1987; Miller et al 1988c) wherein both the donor $\left(\mathrm{D}^{+}\right)$and acceptor $\left(\mathrm{A}^{-}\right)$ions, each having a spin $S=1 / 2$ (where unpaired spins reside on $d$ - and p-orbitals, respectively) are alternately stacked (figure $4 \mathrm{a}$ ). It has a Curie temperature of $4.8 \mathrm{~K}$, and exhibits a field-dependent magnetic hysteresis with a coercive field of $\sim 1 \mathrm{kG}$ at $2 \mathrm{~K}$. The saturation magnetization value for single crystals in a direction parallel to $\mathrm{D}^{+} \mathrm{A}^{-} \mathrm{D}^{+} \mathrm{A}^{-}$stacking axis was $36 \%$ greater than that for pure iron on a gram-atom basis (Miller et al 1988a). ${ }^{57} \mathrm{Fe}$ Mossbauer spectra for this complex, recorded under zero applied field, confirmed large internal fields of $400-450 \mathrm{kG}$ at $4.3 \mathrm{~K}$ (Miller et al $1988 \mathrm{a}, \mathrm{b})$. It is believed that spin polarisation in $\left[\mathrm{Fe}\left(\mathrm{C}_{5} \mathrm{Me}_{5}\right)_{2}\right]^{+}$units leads to a large positive spin density around the iron atom and some negative spin density at the periphery around the $\mathrm{C}_{5} \mathrm{Me}_{5}$ rings. Coupling with a radical line $[\mathrm{TCNE}]^{-}$in a donoracceptor stack may then become ferromagnetic (figure $4 b$ ). Use of higher spin molecular components led to increased intramolecular spin-spin interactions and a higher value of $T_{\mathrm{c}}=6.2 \mathrm{~K}$ for the bulk $3 \mathrm{D}$ ferromagnet $\left[\mathrm{Mn}\left(\mathrm{C}_{5} \mathrm{Me}_{5}\right)_{2}\right]^{+}[\mathrm{TCNQ}]^{-}$, where $S_{\mathrm{D}}=1$ and $S_{\mathrm{A}}=1 / 2$ (Broderick et al 1990). Substitution of a smaller acceptor anion [TCNE] $]^{-}$should lead to a greater spin interaction, which was indeed the case, since a higher $T_{\mathrm{c}}$ of $8.8 \mathrm{~K}$ is observed for $\left[\mathrm{Mn}\left(\mathrm{C}_{5} \mathrm{Me}_{5}\right)_{2}\right]^{+}[\mathrm{TCNE}]^{-}$, where, too, $S_{\mathrm{D}}=1$ and $S_{\mathrm{A}}=1 / 2$ (Yee et al 1991). Subsequently, Miller's group extended the reaction to the $\left[\mathrm{V}\left(\mathrm{C}_{6} \mathrm{H}_{6}\right)_{2}\right]^{+}$donor which is isoelectronic to $\left[\mathrm{Mn}\left(\mathrm{C}_{5} \mathrm{Me}_{5}\right)_{2}\right]^{+}$, and isolated a highly disordered covalently bound polymeric $\mathrm{V}(\mathrm{TCNE})_{x . y}$ (solvent) magnet with a $T_{\mathrm{c}}$ exceeding room temperature ( $400 \mathrm{~K}$ ) (Manriquez et al 1991). However, it is reported to be metastable. Bulk ferromagnetism $\left(T_{c}=18 \mathrm{~K}\right)$ has been reported, subsequently, for a stable covalently bonded extended linear chain (1D) metallomacrocyclic complex $\left[\mathrm{Mn}^{\mathrm{III}} \mathrm{TPP}\right]^{+}[\mathrm{TCNE}]^{-}$where TPP is mesotetraphenylporphinato (Miller et al 1992).

\section{Materials assembled from ferrimagnetic subunits}

Synthesis of molecular ferrimagnets provides a convenient route to overcome the difficulties related with imposing parallel alignment of moments on the scale of the lattice while designing ferromagnets. A clever strategy, therefore, is to design quasi-one 

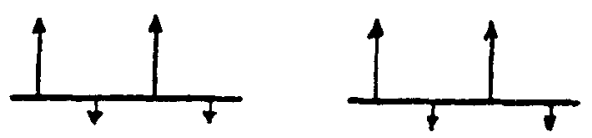

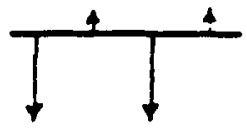

(a)

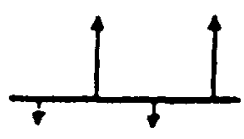

(b)

Figure 5. Two different ways of assembling bimetallic ferrimagnetic chains in a lattice giving rise to (a) antiferromagnetic, or (b) ferromagnetic order. The size of the arrows indicates the magnitude of spin.

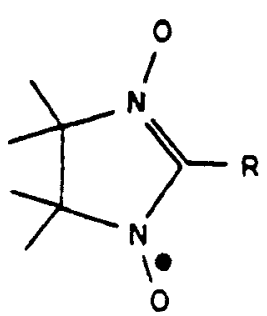

(a)

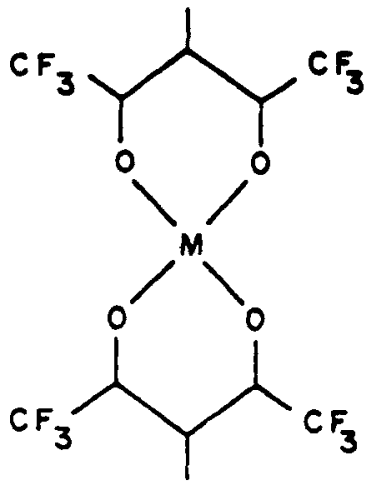

(b)

Figure 6. The radicals (a) NITR, and (b) metal hexafluoroacetylacetonate. The black dot indicates an unpaired electron.

dimensional ferrimagnetic chains, comprising antiparallel alignment of uncompensated $\left(S_{\mathrm{A}} \neq S_{\mathrm{B}}\right)$ spins, and then position them in a bulk lattice in such a way as to provide a net ferromagnetic alignment of spins, as shown in figure $5 \mathrm{~b}$ where the interchain separation is shortest for the unequal spins $S_{\mathrm{A}}$ and $S_{\mathrm{B}}$. It is easy to see that if equal spin sites are located facing each other in adjacent chains, antiferromagnetism results (figure 5a).

Two parallel approaches have been followed to construct the basic ferrimagnetic subunits for the synthesis of this class of organic ferromagnets, viz (i) the metal-radical approach, where one alternates a metal ion spin ( $d$ orbital based) with an organic radical with unpaired spin ( $p$ orbital based) and (ii) the bimetallic approach, where two dissimilar metal-ion spins are alternated with intervening organic bridging groups used to transmit the spin-spin interactions.

\subsection{Metal radical approach}

Gatteschi's group has pioneered the use of the metal-radical approach to assemble extended lattices (Caneschi et al 1989a; Gatteschi and Sessoli 1992). The organic 
radicals used are the nitronyl nitroxides NITR (for 2-R-4,4,5,5-tetramethyl-4,5dihydro-1H-imidazolyl-1-oxy-3-oxide and $\mathrm{R}$ denotes methyl, ethyl, phenyl or propyl groups) (figure 6a) which are stable radicals having $\mathrm{N}-\mathrm{O}$ groups with one unpaired electron in a $\pi^{*}$ orbital and can be used as ligands towards many different metal ions. When the nitroxide binds through its oxygen atom to a paramagnetic metal ion, in say a metal hexafluoroacetylacetonate (figure $6 \mathrm{~b}$ ), the spins can orient, and the exchange interaction can be transmitted without attenuation, since the unpaired electron is delocalised on the two equivalent $\mathrm{N}-\mathrm{O}$ groups. Ferromagnetic compound $\mathrm{Mn}(\mathrm{hfac})_{2}$ NITEt with $T_{\mathrm{c}}=8.1 \mathrm{~K}$ has been thus designed from quasi $1 \mathrm{D}$ ferrimagnetic chains built up of $\operatorname{Mn}^{(\mathrm{II})}(S=5 / 2)$ and NITEt $(S=1 / 2)$ spins (Caneschi et al 1989c). Other examples are the bulk 3D ferromagnet $\mathrm{Mn}(\mathrm{hfac})_{2} \mathrm{NIT}-i$-Pr with $T_{\mathrm{c}}=7.6 \mathrm{~K}$ (Caneschi et al 1989b). the $S=1 / 2$ Heisenberg antiferromagnet $\mathrm{Y}(\mathrm{hfac})_{3} \mathrm{NITEt}$ with $T_{\mathrm{N}}=6 \mathrm{~K}$ (Benelli et al 1989), the ferromagnet $\left[\mathrm{Mn}\left(\mathrm{F}_{5} \mathrm{Benz}\right)_{2}\right]_{2}$ NITEt with $T_{\mathrm{c}}=21 \mathrm{~K}$ (Caneschi et al 1989d) and the 1D Heisenberg ferromagnet $\mathrm{Cu}(\mathrm{hfac})_{2}$ NIT-i-Pr (Cabello et al 1990).

Iwamura's group (Inoue and Iwamura 1994; Inoue et al 1996) has recently utilised high-spin $\pi$-conjugated polynitroxides as bridging ligands to construct transition metal polymer complexes with ferromagnetic characteristics. The diradical (figure 7a) has a triplet ground state $(S=1, J>0)$, with spin density being localised at $\mathrm{N}-\mathrm{O}$ moieties. It forms a $1 \mathrm{D}$ chain if ligated antiferromagnetically with an $\mathrm{Mn}$-ion when complexed with $\mathrm{Mn}^{\mathrm{II}}(\mathrm{hfac})_{2}$. But one obtains only a metamagnetic state below $5.5 \mathrm{~K}$ in this case because the interchain interaction between such $1 \mathrm{D}$ array of spins is quite weak, in the form of superexchange through $F$ atoms (Inoue and Iwamura 1994a). However, increasing the dimensionality of the subunits has led to very encouraging results. A hexagonal 2D graphite-like layered structure is obtained when a 3:2 complex is formed from the trinitroxide radical $(S=3 / 2)$ (figure $7 \mathrm{~b}$ ) and $\mathrm{Mn}^{\mathrm{II}}(\mathrm{hfac})_{2}$, and the McConnell mechanism gives rise to ferromagnetic layer stacking $\left(T_{\mathrm{c}}=3.4 \mathrm{~K}\right.$ ) (Inoue and Iwamura 1994b). More interestingly, the use of a quartet triradical (figure 7c) in<smiles>CON(c1cccc(N([O])C(C)(C)C)c1)C(C)(C)C</smiles>

(a)<smiles>CON(c1ccc(-c2cc(-c3ccc(N([O])C(C)(C)C)cc3)cc(-c3ccc(N([O])C(C)(C)C)cc3)c2)cc1)C(C)(C)C</smiles><smiles>CN(c1cc(N([O])C(C)(C)C)cc(C(C)(C)C)c1)c1cc(N([O])C(C)(C)C)cc(C(C)(C)C)c1</smiles>

(b)

Figure 7. High-spin polynitroxides used to construct TM polymer complexes. 
a similar 3:2 complex gives rise to a 3D network using the middle nitroxide group to interlink the chains, which results in ferromagnetic behaviour at $46 \mathrm{~K}$ (Inoue et al 1996).

\subsection{Bimetallic approach}

Olivier Kahn and co-workers have employed ordered bimetallic ferrimagnetic chains containing, for instance, alternating $\mathrm{Mn}^{\mathrm{II}}(S=5 / 2)$ and $\mathrm{Cu}^{\mathrm{II}}(S=1 / 2)$ spin sites and have synthesized a large number of binuclear molecular magnets such as $\mathrm{MnCu}(\mathrm{obbz})$. $1 \mathrm{H}_{2} \mathrm{O}\left(T_{\mathrm{c}}=14 \mathrm{~K}\right)$ ( Nakatani et al 1989$), \mathrm{MnCu}(\mathrm{pbaOH})($ pyrazine $)\left(\mathrm{H}_{2} \mathrm{O}\right)\left(T_{\mathrm{N}}=2.7 \mathrm{~K}\right)$ (Nakatani et al 1990) and $\mathrm{MnCu}(\mathrm{obze})\left(\mathrm{H}_{2} \mathrm{O}\right)_{2}\left(T_{\mathrm{c}}=4.6 \mathrm{~K}\right)$ (Pei et al 1991), and have obtained interesting information on the magnetic interactions involved. In the case of the ferromagnet $\mathrm{MnCu}(\mathrm{pbaOH})\left(\mathrm{H}_{2} \mathrm{O}\right)_{3}\left(T_{\mathrm{c}}=4.6 \mathrm{~K}\right)$ warming the compound at $100^{\circ} \mathrm{C}$ for $48 \mathrm{~h}$ causes removal of one water molecule, thus increasing the interchain exchange interaction $\left(J_{\text {inter }}\right)$ sharply and bringing about a sharp rise in $T_{c}$ for $\mathrm{MnCu}(\mathrm{pbaOH})$ $\left(\mathrm{H}_{2} \mathrm{O}\right)_{2}\left(T_{\mathrm{c}}=30 \mathrm{~K}\right)$ (Nakatani et al 1991). More recently, Kahn's group has reported the synthesis of a number of ferromagnets containing $\mathrm{Co}(\mathrm{II})$ and $\mathrm{Cu}(\mathrm{II})$ with $\left(T_{\mathrm{c}}>30 \mathrm{~K}\right.$; viz. $\left(\mathrm{NBu}_{4}\right)_{2} \quad \mathrm{Co}_{2}[\mathrm{Cu}(\mathrm{opba})]_{3} \cdot 3 \mathrm{DMSO} \cdot 3 \mathrm{H}_{2} \mathrm{O}$ with $T_{\mathrm{c}}=32 \mathrm{~K}$ and $\left(\mathrm{NBu}_{4}\right)_{2} \mathrm{Co}_{2}-$ $[\mathrm{Cu}(\mathrm{opba})]_{3} \cdot 2 \mathrm{H}_{2} \mathrm{O}\left(T_{\mathrm{c}}=34 \mathrm{~K}\right)$ (Stumpf et al 1994) and $\mathrm{CoCu}(\mathrm{pbaOH})\left(\mathrm{H}_{2} \mathrm{O}\right)_{2}$ $\left(T_{\mathrm{c}}=38 \mathrm{~K}\right)$ (Turner et al 1996). Okawa et al (1994) have used alternating arrays of $\mathrm{Cr}^{2}{ }^{2}$ and $\mathrm{M}^{\mathrm{II}}$ through oxalato bridges to obtain ferromagnetic behaviour below $14 \mathrm{~K}$ for $\left\{\left(\mathrm{NBu}_{4}\right) \cdot\left[\mathrm{Ni}^{\mathrm{II}}\left(\mathrm{Cr}^{\mathrm{III}}(\mathrm{ox})_{3}\right)\right]\right\}$. Changing the bridging group from oxalato to dithiooxalate (dto) yields ferromagnetism in $\left\{\left(\mathrm{NPr}_{4}\right)\left[\mathrm{M}^{\mathrm{II}} \mathrm{Cr}^{\mathrm{III}}(\mathrm{dto})_{3}\right]\right\}_{\mathrm{x}}$ at $T_{\mathrm{c}}=8,16$ and $23 \mathrm{~K}$ for $\mathrm{M}=\mathrm{Fe}$, Co and $\mathrm{Ni}$.

We have carried out some studies recently on binuclear systems. DC magnetization data for the compound $\mathrm{MnCu}(\mathrm{obbz}) \cdot n \mathrm{H}_{2} \mathrm{O}$ after dehydration $\left(T_{\mathrm{c}}=15 \mathrm{~K}\right)$ are shown in figure 8. Detailed magnetization and TG studies conducted on this $\mathrm{MnCu}$-system

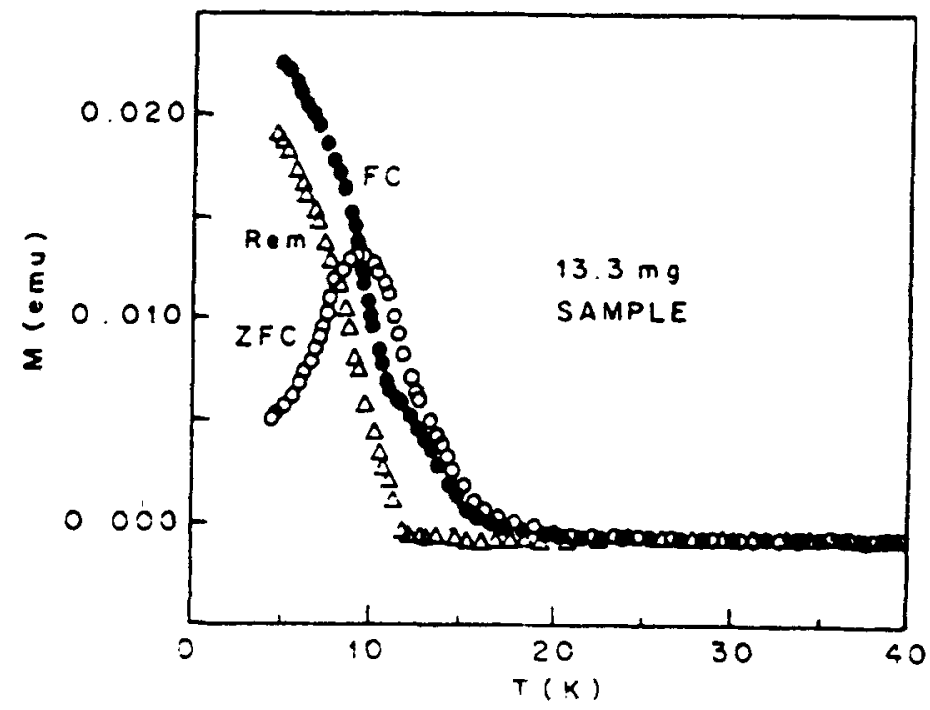

Figure 8. DC magnetization (VSM) data on $\mathrm{MnCu}(\mathrm{obbz}) \cdot n \mathrm{H}_{2} \mathrm{O}$ after dehydration. ZFC, FC and Rem denote the plots corresponding to zero-field cooling, field cooling and remanent magnetization (Chavan et al 1995b) 


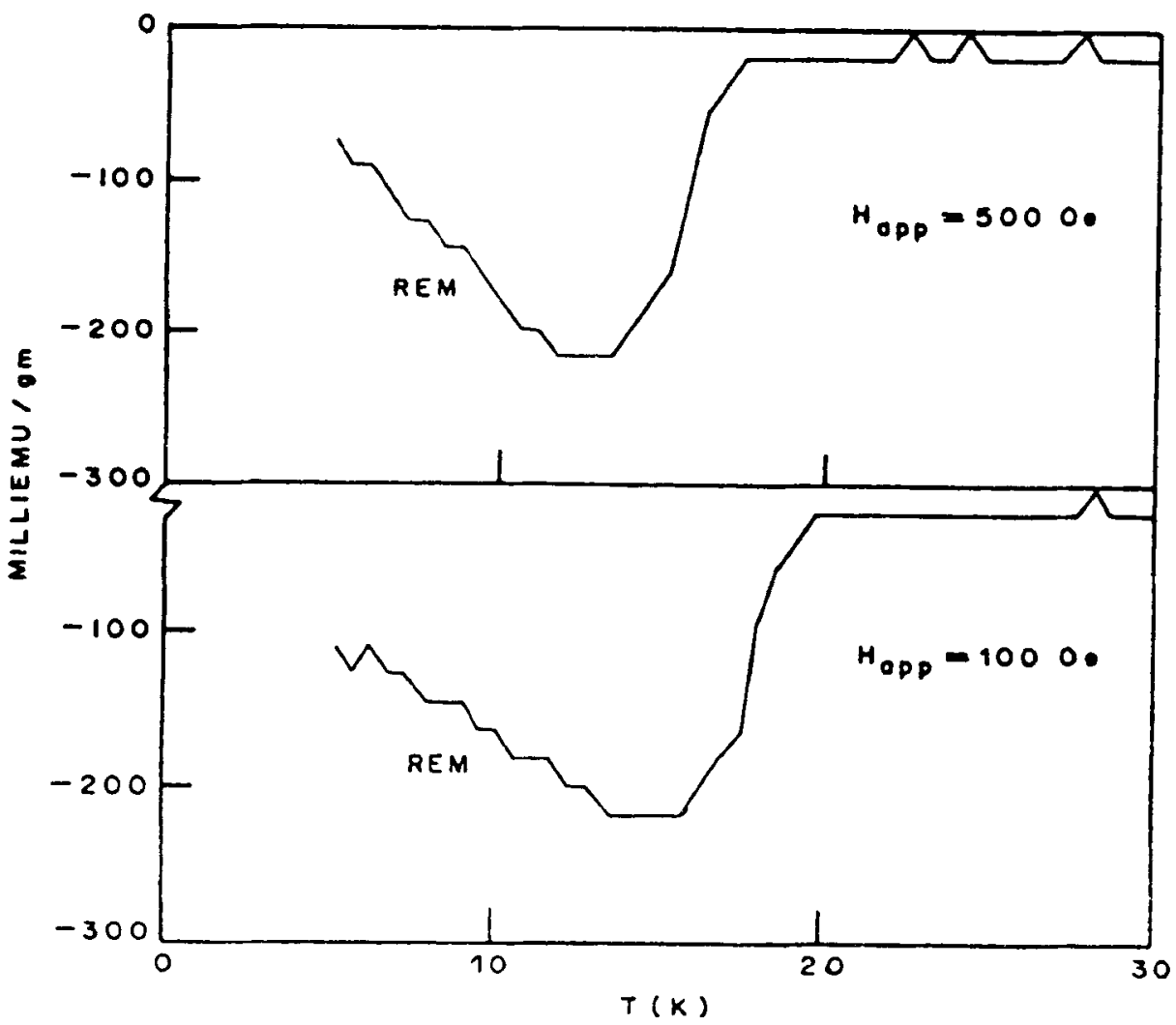

Figure 9. Negative remanence observed for $\left(\mathrm{NBu}_{4}\right)_{2} \mathrm{Mn}_{2}[\mathrm{Cu}(\text { opba })]_{3}\left(T_{\mathrm{c}}=22 \mathrm{~K}\right)$ after it was cooled to $5 \mathrm{~K}$ in applied fields of $100 \mathrm{Oe}$ and $500 \mathrm{Oe}$, respectively (Chavan et al 1996b).

indicate that the number of non-coordinated water molecules which govern the through-space interaction is the system is uncertain (Chavan et al 1995b). The compound $\mathrm{CoCu}(\mathrm{obbz}) \cdot 2 \mathrm{H}_{2} \mathrm{O}$ gives magnetic data consistent with a $1 \mathrm{D}$ ferrimagnet (Chavan et al 1996a). Our recent studies on the opba-based $\mathrm{Mn}_{2} \mathrm{Cu}_{3}$ compounds $\left(\mathrm{NBu}_{4}\right)_{2} \mathrm{Mn}_{2}[\mathrm{Cu}(\text { opba })]_{3} \cdot 6 \mathrm{DMSO} \cdot 1 \mathrm{H}_{2} \mathrm{O} \quad\left(T_{\mathrm{c}}=15 \mathrm{~K}\right)$, its desolvated analogue $\left(\mathrm{NBu}_{4}\right)_{2} \mathrm{Mn}_{2}[\mathrm{Cu} \text { (opba) }]_{3}\left(T_{\mathrm{c}}=22 \mathrm{~K}\right)$ and ferromagnets obtained after solvating the latter with acetonitrile and methanol have shown an interesting new magnetization feature, negative remanence, in the ordered state (figure 9), which we believe arises from the typical nature of the $\mathrm{MnCu}$-ferrimagnetic units from which these opba ferromagnets are constructed (Chavan et al 1996b,c). Muon spin relaxation (Cywinski et al 1996) and EPR (Kadam et al 1996a,b) studies conducted by us recently on $\mathrm{MnCu}(\mathrm{obbz}) \cdot 1 \mathrm{H}_{2} \mathrm{O}$ and $\left(\mathrm{NBu}_{4}\right)_{2} \mathrm{Mn}_{2}[\mathrm{Cu}(\mathrm{opba})]_{3} \cdot \mathrm{DMSO} \cdot 1 \mathrm{H}_{2} \mathrm{O}$ have shown the co-existence of long-range ferromagnetic order and spin fluctuations both above and below Curie temperatures in these soft ferromagnets.

\section{Inorganic molecular compounds}

Ferromagnetic behaviour is known to arise in Prussian Blue salt, ferric ferrocyanide $\mathrm{F}_{4}^{\mathrm{III}}\left[\mathrm{Fe}^{\mathrm{II}}(\mathrm{CN})_{6}\right]_{3} \cdot 15 \mathrm{H}_{2} \mathrm{O}$. But its $T_{\mathrm{c}}$ is low $(5 \cdot 6 \mathrm{~K})$ because the spin carriers $\mathrm{Fe}^{\mathrm{III}}$ are 


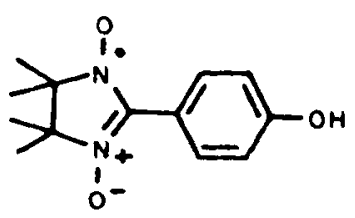

(a)

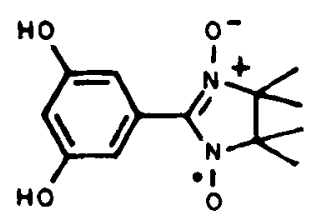

(o)

Figure 10. Examples of substituted phenyl $\alpha$-nitronyl aminoxyl radicals with one (a) or two (b) hydroxylic groups in the aromatic ring.

located 10.6 $\AA$ away. Recently, ferromagnetism has been reported in $\mathrm{Cs}^{\mathrm{I}} \mathrm{Ni}^{\mathrm{II}}\left[\mathrm{Cr}^{\mathrm{III}}(\mathrm{CN})_{6}\right]$ $2 \mathrm{H}_{2} \mathrm{O}$ below $90 \mathrm{~K}$, and ferrimagnetic behaviour observed in a number of hexacyanometalates (Prussian Blue analogues) with the general formula $\mathrm{A}_{k}\left[\mathrm{~B}(\mathrm{CN})_{6}\right]_{i} \cdot n \mathrm{H}_{2} \mathrm{O}$. with alternating $\mathrm{A}$ and $\mathrm{B}$ metal ions having non-zero spins in octahedral surroundings in an $f c c$ cell. Examples are $\mathrm{Cs}_{2} \mathrm{Mn}^{\mathrm{II}}\left[\mathrm{V}^{\mathrm{II}}(\mathrm{CN})_{6}\right]$ with $T_{\mathrm{c}}=125 \mathrm{~K}$ (Entley and Girolami 1994) and $\left(\mathrm{V}_{0.42}^{\mathrm{II}} \mathrm{V}_{0.58}^{\mathrm{III}}\right)\left[\mathrm{Cr}^{\mathrm{III}}(\mathrm{CN})\right]_{086} \cdot 2 \cdot 8 \mathrm{H}_{2} \mathrm{O}$ with $T_{\mathrm{c}}=315 \mathrm{~K}$ (Ferlay et al 1995). Ohba et al (1994) have designed a new bimetallic ferromagnet $\left(T_{c}=18.6 \mathrm{~K}\right)$ with a rope-ladder chain structure having a formula $\left[\mathrm{Ni}(\mathrm{en})_{2}\right]_{3}\left[\mathrm{Fe}(\mathrm{CN})_{6}\right]_{2} \cdot 2 \mathrm{H}_{2} \mathrm{O}$ where en $=1$, 2, ethanediamine.

\section{Use of hydrogen bonds}

Borrowing the idea from nature, which uses non-covalent interactions such as hydrogen bonds, in a very economical and successful way for molecular self-assembly of superstructures at the cellular level, some research groups have attempted the use of hydrogen bonds between open-shell molecules to obtain supramolecular self-organisation aimed at achieving intermolecular ferromagnetic interactions along pre-established spatial directions utilising the high degree of directionality displayed by $\mathrm{H}$-bonds (Cirujeda et al 1995a,b). The H-bonds provide intermolecular contacts among atoms with positive and negative spin densities giving rise to ferromagnetic interactions when $2 \mathrm{D}$ networks of hydroxylated phenyl $\alpha$-nitronyl nitroxides (figure 10) are self-assembled. Akita et al (1995) have obtained ferromagnetic behaviour at $30 \mathrm{~K}$ ascribed to $\mathrm{H}$-bonds in the 1:1 complex between phenyl nitronyl nitroxide and phenyl boronic acid, the latter being used as a spin coupler for enhanced spin interaction between neighbouring nitroxide radical centres.

\section{Conclusions}

A deeper understanding of the guiding principles of molecular magnetism is evolving as a result of extensive studies being conducted in many laboratories. Efforts are now being directed towards exploration of complex cooperative systems so that syntheses of nanoscale magnetic particles become possible. Given the present rate of growth in this multidisciplinary field, the next decade may witness the design of or ganic ferromagnets with improved magnetic properties to enable their use in devices.

\section{Acknowledgements}

The authors thank the Indo-French Centre for the Promotion of Advanced Research, New Delhi for financial support under the Project Grant \# 1308-4. SAC also thanks the Department of Atomic Energy, Mumbai for a fellowship. 


\section{References}

Akita T, Mazaki Y and Kobayashi K 1995 J. Chem. Soc. Chem. Commun. 1861

Allemand P M, Khemani K C, Koch A. Wudl F. Holezer K. Donovan S. Gruner G and Thompson J D 1991 Science 253301

Ata M, Machinda M, Watanabe H and Seto J 1994 Jpn. J. Appl. Phys. 331865

Awaga K. Sugano T and Kinoshita M 1986 Solid State Commun. 57453

Benelli C, Caneschi A, Gatteschi D, Pardi L and Rey P 1989 Inorg. Chem. 283230

Broderick W E, Thompson J A, Day E P and Hoffman B M 1990 Science 249401

Cabello C A, Caneschi A, Carlin R L, Gatteschi D, Rey P and Sessoli R 1990 Inorg. Chem. 292582

Caneschi A, Gatteschin D, Sessoli R and Rey P 1989a Acc. Chem. Res. 22392

Caneschi A, Gatteschi D, Renard J P, Rey P and Sessoli R 1989b Inorg. Chem. 281976

Caneschi A, Gatteschi D, Renard J P, Rey P and Sessoli R 1989c Inorg. Chem. 283314

Caneschi A, Gatteschi D, Renard J P, Rey P and Sessoli R 1989d J. Am. Chem. Soc. 111785

Chavan S A, Yakhmi J V and Gopalakrishnan 1 K 1995a Mater Sci. Eng. C3 175

Chavan S A, Yakhmi J V and Gopalakrishnan 1 K 1995b Mol. Cryst. Liq. Cryst. 27411

Chavan S A, Yakhmi J V and Kahn O 1996a (to be published)

Chavan S A, Yakhmi J V, Ganguly R and Jain V K 1996b Curr. Sci. 70234

Chavan S A, Ganguly R, Jain V K and Yakhmi J V 1996c J. Appl. Phys. 795260

Chiarelli R, Novak M A, Rassat A and Tholence J L 1993 Nature (London) 363147

Chittipedi S, Cromak K R, Miller J S and Epstein A J 1987 Phys. Rev. Lett. 582695

Cirujeda J, Gasio E H, Rovira C, Stanger J -L, Turek P and Veciana J 1995a J. Mater. Chem. 5243

Cirujeda J, Mas M, Molins E, de Panthau F L, Laugier J, Park J G, Paulsen C, Rey P, Rovira C and Veciana J 1995b J. Chem. Soc., Chem. Commun. 709

Cywinski R, Yakhmi J V, Chavan S A, Cottrell S P and Kahn O 1996 Synth. Met (accepted)

Entley W R and Girolami G S 1994 Science 268397

Fang Z, Liu Z L and Yao K L 1994 Phys. Rev. B49 3916

Ferlay S, Mallah T, Ouahes R. Veillet P and Verdaguer M 1995 Nature (London) 378701

Gatteschi D and Sessoli R 1992 J. Magn. Mater. 104-107 2092

Gatteschi D, Caneschi A, Pardi L and Sessoli R 1994 Science 2651054

Inoue K and Iwamura H 1994a J. Chem. Soc., Chem. Commun. 2273

Inoue K and Iwamura H 1994b J. Am. Chem. Soc. 1163173

Inoue K, Hayamizu T, Iwamura H, Hashizume D and Ohashi Y 1996 J. Am. Chem. Soc. 1181803

Ishida T, Tsuboi H, Nogami T, Yoshikawa H, Yasui M, Iwasaki F, Iwamura H, Takeda N and Ishikawa M 1994 Chem. Lett. 919

Kadam R M, Sastry M D. Chavan S A, Yakhmi J V and Kahn O 1996a Mol. Cryst. Liq. Cryst. (to appear)

Kadam R M, Sastry M D. Chavan S A, Yakhmi J V and Kahn O 1996b To be presented at the Int. Symp. on Crystalline Organic Metals, Superconductors and Ferromagnets, ISCOM'97, March 22-26, 1997, Sesimbra, Portugal

Kahn O 1993 Molecular magnetism (New York: Verlag-Chemie)

Kahn O, Pei Y and Journaux Y 1992 In Inorganic materials (eds) D W Bruce and D O 'Hare(New York: John Wiley) p. 59

Katulevskii Y A, Magrupov M A and Muminov A A 1991 Phys. Status Solidi A127 223

Korshak Y V, Ovchinnikov A A, Shapiro A M, Medvedeva T V and Spector V N 1986 JETP Lett 43399

Korshak Y V, Medvedeva T V, Ovchinnikov A A and Spector V N 1987 Nature (London) 326 370

Manriquez J M, Yee G T, McLean R S, Epstein A J and Miller JS 1991 Science 2521415

Mataga N 1968 Theor. Chim. Acta 10372

McConnell H M 1963 J. Chem. Phys. 391910

McConnell H M 1967 Proc. Robert A. Welch Found. Conf. Chem. Res. 11114

Miller J S and Epstein A J 1994 Angew. Chem., Int. Ed. Engl. 33385

Miller J S, Calabrese J C, McLean R S and Epstein A J 1982 Adv. Mater. 4498

Miller J S, Calabrese J C, Epstein A J, Bigelow R W, Zhang J H and Reiff W M 1986 J. Chem. Soc., Chem. Commun. 1026 
Miller J S, Epstein A J and Reiff W M 1988a Chem. Rev. 88201

Miller J S, Epstein A J and Reiff W M 1988b Acc. Chem. Res. 21114

Miller J S, Epstein A J and Reiff W M 1988c Science 24040

Murray M M, Kaszynski P, Kaisaki D A, Chang W and Dougherty D A $1994 \mathrm{~J}$. Am. Chem. Soc.116 8152

Nakamura N, Inoue and Iwamura H 1993 Angew. Chem., Int. Ed. Engl. 32872

Nakatani K, Carriat J Y, Journaux Y, Kahn O, Lloret F, Renard J P, Pei Y, Sletten J and Verdaguer M $1989 \mathrm{~J}$. Am. Chem. Soc. 1115739

Nakatani K, Kahn O, Mathoniere C, Pei Y and Zakine C 1990 New. J. Chem. 14861

Nakatani K, Bergerat P, Codjovi E, Mathoniere C, Pei Y and Kahn O 1991 Inorg. Chem. 303978

Nakazawa M, Tamura M, Shirakawa N, Shiomi D, Takahashi $\mathbf{M}$, Kinoshita $\mathbf{M}$ and Ishikawa M 1992 Phys. Rev. B46 8906

Nogami T, Tomioka K, Ishida T, Yoshikawa H, Yasui M, Iwasaki F, Iwamura H, Takeda N and Ishikawa M 1994 Chem. Lett. 29

Ohba M, Moruno N, Okawa H, Enoke T and Latour J M 1994 J. Am. Chem. Soc. 11611566

Okawa H, Mitsumi M, Ohba M, Kodera M and Matsumoto N 1994 Bull. Chem. Soc. Jpn. 67 2139

Ota M, Otani S and Igarashi M 1989 Chem. Lett. 1183

Ovchinnikov A A 1978 Theor. Chim. Acta 47297

Pei Y, Kahn O, Nakatani K, Codjovi E, Mathoniere C and Sletten J 1991 J. Am. Chem. Soc.113 6558

Ribas J, Monfort M, Solans X and Drillon M 1994 Inorg. Chem. 33742

Stephens P W, Cox D, Lauher J W, Mihaly L, Wiley J B, Allemand P M, Hirsch A, Holczer K, Li Q, Thompson J D and Wudl F 1992 Nature (London) 355331

Stumpf H O, Pei Y, Michaut C, Kahn O, Renard J P and Ouahab L 1994 Chem. Mater. 6257

Sugawara T, Matsushita M, Izuoka A, Wada N, Takada N and Ishikawa M 1994 J. Chem. Soc., Chem. Commun. 1723

Tamura M, Nakazawa Y, Shiomi D, Nozawa K, Hosokashi Y, Ishikawa M, Takahashi M and Kinoshita M 1991 Chem. Phys. Lett. 186401

Tanaka H, Tokuyama K, Sato T and Ota T 1990 Chem. Lett. 1813

Turner S, Kahn O and Rabardel L $1996 \mathrm{~J}$. Am. Chem. Soc. (to appear).

Yakhmi J V 1992 Solid State Phys. (India) 353

Yee G T, Manriquez J M, Dixon D A, McLean R S, Groski D M, Flippen R B, Narayan K S, Epstein A J and Miller J S 1991 Adv. Mater. 3309

Yoshizawa K, Tanaka K and Yamabe T 1993 Synth. Met. 60279 